\title{
Comprehensive Analysis and Evaluation of Cogging Torque in Axial Flux Permanent Magnet Machines
}

\author{
A. P. Ferreira, Member, IEEE, A. V. Leite, Member, IEEE and A. F. Costa
}

\begin{abstract}
Evaluation and minimization of cogging torque in Axial Flux Permanent Magnet (AFPM) machines become essential specially in direct drives for low speed applications. This paper presents a comprehensive analysis of the cogging torque in AFPM machines designed for low speed applications and mitigation methods are proposed. Evaluation methodologies of the cogging torque based on Finite Element Analysis (FEA) computations are discussed and applied to a double-sided, internal rotor, AFPM reference machine. From the performance comparison of Maxwell stress tensor and virtual work methods on the evaluation of cogging torque, it is possible to conclude that the latter overestimates the amplitude of the cogging torque into a considerable extent.
\end{abstract}

Index Terms - Axial flux permanent magnet machines, Cogging torque, Finite-element method, Maxwell stress tensor, Method of virtual work.

\section{INTRODUCTION}

A XIAL FLUX permanent magnet (AFPM) machines are very well suited for low speed applications due to their higher torque to volume ratio in multi-pole solutions, preventing the use of a gearbox for speed and torque conversions. The ability of these machines to be designed for a conversion system as direct drives has many advantages such as lowering components and its maintenance schemes, reduced mechanical losses and noise. In spite of the advantages of this trend, direct drive conversion systems for low speed applications exacerbate undesirable effects of torque pulsations in the machine, as there is no gearbox able to lessen them [1].

Torque pulsations in direct drive AFPM machines for low speed applications may result from the interaction of current harmonics and permanent magnet (PM) field, the so called torque ripple, whose severity varies with the extent of the armature reaction. Other source of torque pulsations is the cogging torque which exists even in the absence of

A. P. Ferreira is with Polytechnic Institute of Bragança, Portugal and CISE - Electromechatronic Systems Research Centre, UBI, Portugal (email: apf@ipb.pt).

A. V. Leite is with Polytechnic Institute of Bragança, Portugal and CISE - Electromechatronic Systems Research Centre, UBI, Portugal (email: avtl@ipb.pt).

A. F. Costa is with the Department of Electrical Engineering, FEUP, Portugal (e-mail: acosta@fe.up.pt). stator currents. This component results from the interaction between the PM field and the stator slots, by varying the air gap reluctance of the magnetic circuit.

Another component that may exist is the reluctance torque, caused by the stator current and the anisotropy of the magnetic circuit of the rotor, which may result from assembling PM embedded into the rotor disk. Due to the low permeability of PM, when interior permanent magnet configuration is used, it leads to an inverse anisotropy of the magnetic circuit, in opposite to surface mounted PM, whereas the magnetic circuit is isotropic [2]. Interior PM configuration reduces the demagnetization risk since the magnets are surrounded by ferromagnetic iron which also protects them against mechanical impacts, wear and corrosion [3]. Additionally, it is possible to achieve nearly sinusoidal air gap flux density and the cogging torque component is significantly reduced [4]. On the other hand, this structure suffers from increased leakage flux and the manufacturing process is more complicated when compared with surface mounted PM.

In order to obtain a simplified construction, AFPM machines are manufactured almost exclusively with surface mounted magnets associated with slotted stators, which reduce the requirements of PM material volume. With this configuration, the equivalent air gap is relatively high, which lessens the ripple and reluctance torque components, whilst cogging torque component is noteworthy. Hence, evaluation and minimization of cogging torque become essential specially in low speed applications where high precision control systems are required.

This paper is organized as follows: the following section presents AFPM machine design issues for low speed applications which may affect the cogging torque profile and introduces the AFPM reference machine used in this study; in section III the main techniques to lessen cogging torque in AFPM machines are reviewed and, further, in sections IV and $\mathrm{V}$, cogging torque computation methodologies based on Finite Element Analysis (FEA) are discussed and applied to a reference design of a doublesided with internal rotor AFPM machine with one slot per pole and phase. Finally, section VI presents the main conclusions of the work and its future developments. 


\section{AXial FluX Permanent Magnet Machine Design}

From a construction point of view, AFPM machines can be designed as single-sided or double-sided (Fig. 1), with embedded or surface PM disk rotors. Regular shaped surface mounted PM rotors are usually preferred due to manufacturing simplicity. In opposition to double-sided topologies, single-sided AFPM machines suffer from unbalanced axial forces between rotor and stator iron and, as consequence, the bearing systems are more complex [5].

Double-sided, internal stator topologies may be coreless if an Halbach array is employed in the rotor structures or, alternatively, use an iron core stator, with or without slots. Halbach magnetized permanent-magnet machines have

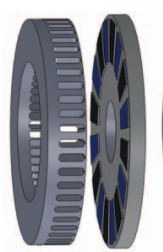

(a)

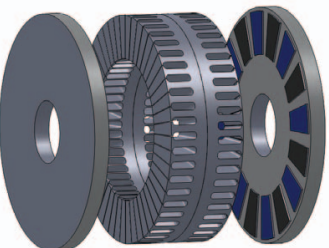

(b)

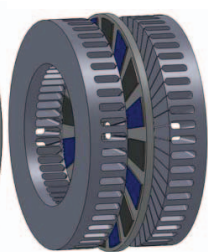

(c)
Fig. 1. Possible configurations of AFPM machines: (a) single-sided AFPM machine; (b) double-sided AFPM machine with internal stator. (c) doublesided AFPM machine with internal rotor.

almost sinusoidal induced electromotive force (EMF) and the torque ripple is in a reasonable range [6-8]. Internal stator topologies degrade the thermal performance of the machine, because copper losses, which are the major losses in low speed machines, are more difficult to remove [9].

Internal rotor configuration prevents the use of an iron core in the rotor structure and iron core stators may be slotted or slotless. The later has advantages such as simple stator assembly, reduction of rotor surface losses and elimination of the cogging torque but, on the other hand, the required volume of $\mathrm{PM}$ material is higher, which represents a major drawback in the overall price of the machine.

In order to prevent scaling problems of the AFPM machines, since the torque capability is proportional to the cube of the diameter, their power range can be increased by using multi-stage configurations, by simply stacking disk machines on the same shaft and in the same enclosure [10].

For surfaced mounted PM rotor configuration with slotted stators, cogging torque is significant and its extent depends on design variables, including the winding arrangement. Winding configurations may be classified as distributed (or overlapping) or concentrated (i.e., nonoverlapping). Concentrated windings favor the reduction of copper losses due to short end turns, improve the flux weakening capability and fault tolerance and allow high slot fill factors $[11,12]$. Distributed overlapping winding results, generally, in a reduced harmonic content of the stator mmf, which reduces torque ripple, and are extensively used in synchronous operation, in opposition to brushless DC operation of PM machines, where concentrated windings prevail. One consequence of the winding arrangement on the cogging torque of the machine is related with the ratio between the number of stator slots necessary to accommodate the windings and the number of rotor poles.

\section{A. AFPM machine reference design}

The reference design of the three-phase machine used in this work is based on the double-sided structure with PM surface internal rotor and slotted stators (Fig. 1 (c)), with $p=10$ pole pairs and $Q=60$ non skewed slots per stator, i.e., with $q=1$ slot per pole and phase, for which the cogging torque amplitude is expected to be high. Trapezoidal-shaped permanent magnets NdFeB are used, accomplishing an efficient pole-arc coefficient for maximum no load flux linkage of 0.6 [13]. Main design parameter of the reference AFPM machine is presented in Table 1 [14].

TABLE I

MAIN DIMENSIONS OF THE AFPM REFERENCE MACHINE

\begin{tabular}{cc}
\hline PARAMETER & VALUE \\
\hline Axial motor length & $5.62 \mathrm{~cm}$ \\
\hline Stator yoke length & $0.86 \mathrm{~cm}$ \\
\hline Air gap thickness & $0.5 \mathrm{~mm}$ \\
\hline Inner radius of the stator iron & $6.5 \mathrm{~cm}$ \\
\hline Outer radius of the stator iron & $9 \mathrm{~cm}$ \\
\hline Permanent magnet axial length & $1 \mathrm{~cm}$ \\
\hline Number of pole pairs & 10 \\
\hline Pole pitch (at average radius) & $2.49 \mathrm{~cm}$ \\
\hline Number of phases & 3 \\
\hline Number of coils per stator & 60 \\
\hline Number of turns per phase and per stator & 480 \\
\hline Number of slots per pole and phase & 1 \\
\hline Rated speed & $600 \mathrm{rpm}$ \\
\hline Rated power & $700 \mathrm{~W}$ \\
\hline Remanent magnetic flux density of PM & $1.12 \mathrm{~T}$ \\
\hline Linear current density (at inner radius) & $13.4 \mathrm{kA} / \mathrm{m}$ \\
\hline RMS no-load phase to neutral voltage per stator \\
(at 600 rpm) & $72.5 \mathrm{~V}$ \\
\hline
\end{tabular}

\section{Mitigation TeCNHIQUes OF COGgING TORQUE IN} AFPM MACHINES

Cogging torque arises due to the interaction between the magnetic flux and the reluctance variation introduced in the air gap by the stator slots openings. The magnetic flux density in the air gap decreases under each slot opening due to an increase in the reluctance, resulting in a change of coenergy as the rotor moves. The cogging torque is periodic and almost symmetric about its angular axis [15].

The periodicity of the cogging torque, i.e., the number of cycles per mechanical revolution is given by the least common multiple of the number of poles and the number of slots per stator, 


$$
N_{c o}=\operatorname{LCM}(Q, 2 p)
$$

Higher frequencies of the cogging torque usually translate on reduced amplitudes and, therefore, are preferred. Without mitigation techniques, its amplitude may rise till $25 \%$ of the rated torque $[15,16]$.

The cogging torque is modeled by a Fourier sum, given by

$$
T_{c o}=\sum_{n=1}^{\infty} T_{n} \sin \left(n N_{c o} \theta+\varphi_{n}\right)
$$

where $T_{n}$ and $\varphi_{n}$ are the amplitude and phase of the $n^{\text {th }}$ harmonic, respectively, and $\theta$ is the rotor rotating position.

Cogging torque minimization techniques may involve control-side methods and design-side methods [17]. The first ones are based on harmonic current injection to produce a torque ripple waveform able to eliminate the cogging component of the torque. Prior to these techniques, designbased techniques should be explored to help avoid pitfalls during realization of AFPM machines. From the cogging torque sources, it is evident that its extent is decreased by reducing the operating PM remanent magnetic flux and/or the reluctance variation over the air gap. The former also reduces the rated performance of the AFPM machine and consequently, decreasing the reluctance variation is the viable solution to mitigate the cogging torque.

For the AFPM machine, attenuating the cogging torque during the process design phase itself may be obtained by combining the slot number per pole and phase, skewing stator slots or PM, varying pole-arc coefficient by shifting alternate pole pairs or using variable magnet width, introducing dummy slots or introducing a rotor or stator displacement in double-sided structures. In theory, all these techniques are possible, but they imply a compromise between manufacturing feasibility, performance rating and cogging torque minimization.

In a recursive design procedure, while testing various cogging torque mitigation techniques, the routine design should monitor the average torque, the back EMF and the flux leakage, in order to maintain the desired performance of machine.

From a practical point of view, effective elimination of cogging torque is never obtained due to fringing effects and due to unavoidable dimensions tolerances in manufacturing process.

\section{A. Stator slot and rotor pole combination}

The number of stator slots and rotor poles dictate in large extent the amplitude and frequency of the cogging torque. As previously introduced, cogging torque amplitude decreases with increasing number of cycles per mechanical revolution. Cogging cycles are usually higher for concentrated windings with fractional number of slots per pole and phase. In this situation, cogging torque components induced by the magnets are out of phase which reduces overall cogging torque [18]. In opposition, if a distributed winding is used, with an integer number of slots per pole and phase, the induced cogging torque components are all in phase which leads to maximum cogging torque. Practical combinations able to reduce the cogging torque without degrading the performance of the machine are proposed in [11], even though they may introduce unbalanced windings in the stator slots.

\section{B. Skewing}

The stator iron core of the AFPM is frequently obtained from strip wound iron sheet in a spiral configuration or segmented stator structures. Skewing slots openings from the radial direction of the AFPM machine, to span the entire cogging cycle, by a "skew" angle,

$$
\theta_{s k}=\frac{2 \pi}{N_{c o}}
$$

can eliminate the cogging torque. In fact, within this angle, the cogging torque is obtained as [15]

$$
\begin{gathered}
T_{s k}=\frac{1}{\theta_{s k}} \int_{0}^{\theta_{s k}} T_{c o}(\theta) d \theta= \\
=\frac{1}{\theta_{s k}} \sum_{n=1}^{\infty} \int_{0}^{2 \pi / N_{c o}} T_{n} \sin \left(n N_{c o} \theta+\varphi_{n}\right) d \theta=0
\end{gathered}
$$

This process increases significantly the manufacturing process and it is not commonly used in this type of machines.

Another alternative within this approach is to skew the magnets by the same angle.

From the view point of manufacturing complexity, in radial flux machines it is easier to implement the skew in the stator laminations and in axial flux machines skewing the magnets is almost straightforward [10, 19]. In fact, the planar air gap allows simple permanent magnets geometries, with a flat surface area and the magnetization process of "skewed" magnets is the same.

\section{Varying the pole-arc coefficient}

The use of a suitable constant pole-arc coefficient reduces the cogging torque. According to [17] pole arc to pole-pitch ratio of about 0.7 minimizes the cogging torque for AFPM machines, but on the other hand, back EMF is distorted and flux linkage is reduced [13], which degrades the output power and torque.

Another approach is using variable pole-arc coefficients for adjacent magnets, which may eliminate some cogging torque components. This method can be implemented varying the magnet width or shifting alternate pole pairs. The disadvantage of these processes is the introduction of asymmetries in the rotor structure and, as consequence, torque ripple may increase.

\section{Dummy slots}

Dummy slots can be introduced by notching the teeth, which leads to an increase of the frequency of the cogging torque. As stated previously, with increased cogging 
frequencies the amplitude of the cogging torque decreases. The dummy slots are not as deep as the slots where windings are positioned but, if feasible, for cogging torque mitigation small notches in the teeth are sufficient [15]. In low speed applications, due to the high number of poles and, consequently, slots required, the width of the teeth would not be enough to accommodate the notches.

Still on the subject regarding the slot and teeth widths, it is as rule of thumb that the optimal ratio between the slot width and the slot pitch is 0.5 [20].

\section{E. Rotor or stator displacement}

In double-sided AFPM machines, the cogging torque results from the superposition of the waveforms in each air gap. An effective way to reduce the cogging torque is using a rotor or stator displacement [21], for internal stator or internal rotor configurations, respectively. In consequence, the back EMF and the average torque are also reduced, but with an appropriate displacement attending the frequency of the cogging torque, it is possible to reduce the later in a larger extent than the average torque.

\section{Computation of the Cogging Torque}

There are two distinct approaches to predict the various components of the torque: analytical and numerical ones. Analytical approaches are suitable for relative simple geometries, but due to oversimplification, they may lead to high inaccuracies and are not suitable for a comprehensive design in high-performance applications. On the other hand, numerical approaches such as FEA, using two dimensional (2D) or three dimensional (3D) modeling, offer more accurate assessments in complex geometries. 2D analysis does not allow modeling border phenomena in the internal and external radii as well as asymmetries that may exist along the active part of the machine. Consideration of these aspects requires $3 \mathrm{D}$ modeling, for which pre-processing and processing are too time consuming, especially when an interaction between the design procedure and the geometry of the machine is required. An alternative is using quasi-3D approach, i.e., the radial length of the machine is divided into a certain number of computation $x y$ planes, assuming that dimensions are not variable on the radial direction $(z$ axis) for a $\Delta r$ extension, allowing 2D modeling to be performed. The overall performance is obtained from the superposition of the results obtained for each computation plane. The number of computational planes to be used should be defined through a sensitivity analysis.

Techniques to compute electromagnetic forces on magnetic devices may be performed by integrating the Maxwell stress tensor (MST) or using the method of virtual work.

\section{A. Maxwell Stress Tensor method}

The method based in the Maxwell stress tensor associated to FEA is one of the most efficient method for accurately computing electromagnetic forces for which the exact distribution of volume forces is not known. In a general electromagnetic context the force density is given by

$$
\frac{d \boldsymbol{F}}{d v}=\boldsymbol{J} \times \boldsymbol{B}
$$

Using the constitutive equation for magnetic fields and the Maxwell-Ampère law, (5) can be written as

$$
\frac{d \boldsymbol{F}}{d v}=\frac{1}{\mu}(\nabla \times \boldsymbol{B}) \times \boldsymbol{B}=-\frac{1}{\mu} \boldsymbol{B} \times(\nabla \times \boldsymbol{B})
$$

Introducing the term $(\nabla \cdot \boldsymbol{B}) \boldsymbol{B}$ in the previous equation and using the differential relationship $\frac{1}{2} \nabla(\boldsymbol{B} \cdot \boldsymbol{B})=\boldsymbol{B} \times(\nabla \times \boldsymbol{B})+(\boldsymbol{B} \cdot \nabla) \boldsymbol{B}, \quad$ the resulting expression is

$$
\frac{d \boldsymbol{F}}{d v}=\frac{1}{\mu}\left[(\nabla \cdot \boldsymbol{B}) \boldsymbol{B}-(\boldsymbol{B} \cdot \nabla)-\frac{1}{2} \nabla(\boldsymbol{B} \cdot \boldsymbol{B})\right]
$$

The multiple terms of (7) can be rewritten in a compact form, through the second order Maxwell tensor [22], given by

$$
\mathrm{T}_{i j}=B_{i} B_{j}-\frac{1}{2} \delta_{i j} B^{2}
$$

where $i, j=x, y$ or $z$ and $\delta_{i j}$ is the Kronecker's delta.

When operating with the divergence operator on the stress tensor [23], (7) can be rewritten as

$$
\frac{d \boldsymbol{F}}{d v}=\frac{1}{\mu} \nabla \cdot \mathrm{T}
$$

Using the divergence theorem, the total force is given by

$$
\boldsymbol{F}=\frac{1}{\mu} \int_{S} \mathrm{~T} \cdot d \boldsymbol{s}
$$

where $S$ is the surface which surrounds the volume of the moving body and $\mu$ is the permeability of the medium whereas the integration is processed. In practice, it is recommended to proceed to the integration in a medium with constant permeability, i.e., in electrical machines, it should be performed in the air gap.

Considering the infinitesimal surface of the AFPM rotor, where $\boldsymbol{d} \boldsymbol{s}=d x d z \boldsymbol{u}_{\boldsymbol{y}}$, and assuming $\boldsymbol{B}=\left(B_{x}, B_{y}, 0\right)$ constant on the integration surface (Fig. 2), the differential force acting on the disk surface of the rotor can be written as

$$
\frac{d \boldsymbol{F}}{d s}=\frac{1}{\mu_{0}}\left(T_{x y}, T_{y y}, T_{z y}\right)=\frac{1}{\mu_{0}}\left(B_{x} B_{y}, B_{y}{ }^{2}-\frac{1}{2} B^{2}, 0\right)
$$

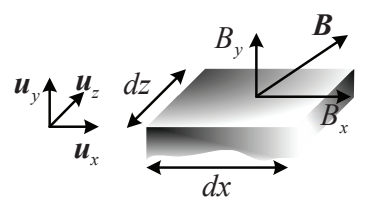

Fig. 2. Infinitesimal surface of the rotor of AFPM machine and components of the magnetic flux density. 
and, finally, from the infinitesimal force on $x$ axis, the torque is evaluated from

$$
T=\frac{1}{\mu_{0}} \int_{S} r B_{x} B_{y} d x d z
$$

being $r$ the distance from the infinitesimal element to the rotation axis.

The integration process in (12) is, formally, a 3D problem, whose transposition to the quasi-3D modeling, previously introduced, is given by

$$
T=\frac{p}{\mu_{0}} \sum_{i=1}^{N} \Delta r_{i} r_{\text {medi }} \int_{0}^{\tau_{i}} B_{x} B_{y} d x
$$

where $\Delta r_{i}, r_{\text {med } i}$ and $\tau_{i}$. are the radial length, the mean radius and the pole pitch for the computation plane $i, p$ is the number of pole pairs of the machine and $N$ is the number of computation planes.

For a magnetic flux density continuously defined, the torque evaluation by this methodology is precise. FEA numerical results of the magnetic flux density are, intrinsically, an approximation and the continuity of magnetic flux density components is not guaranteed. Therefore, the precision of the obtained results is dictated by the adopted mesh in the integration domain.

\section{B. Method of virtual work}

Another technique for computing forces and torques is derived from the electromagnetic energy of the system, studying the effect of a small displacement.

To compute the cogging torque, in the absence of the stator mmf, there is no variation of electric energy and, therefore, for an infinitesimal displacement of the rotor position, $d \theta$, the sum of the magnetic energy in the system and the work done by the magnetic field is null, i.e.,

$$
T_{\operatorname{cog}}=-\frac{d W_{m}}{d \theta}
$$

This technique is, apparently, simple but due to the presence of the PM, the work done by the magnetization in the virtual displacement is irreversible, which may lead to inaccurate results.

\section{Numerical COMPutation of the Cogging Torque FOR THE AFPM REFERENCE MACHINE}

The cogging torque of the AFPM reference machine introduced in section II, is evaluated based on FEA results, using the MST and the method of virtual work, presented in the previous section. FEA is carried out through COMSOL Multiphysics software, AC/DC module [24].

The average of the electromagnetic torque, in rated load condition, estimated through MST, is 11 N.m.

The overlapping stator winding using $q=1$ slot per pole and phase gives rise to a cogging torque with a periodicity of one slot pitch, i.e., $\pi / 30$ electrical degrees. The evaluation of the cogging torque is performed using 20 incremental rotor positions in its period.

Regarding the method of virtual work, the magnetic energy variation and the corresponding function, obtained through the Fourier coefficients is presented in Fig. 3.

With the purpose of comparing the cogging torque evaluated by the two proposed methodologies, obtained results from MST and virtual work are superimposed in Fig. 4. The harmonic content of the cogging torque evaluated by the MST is shown in Fig. 5.

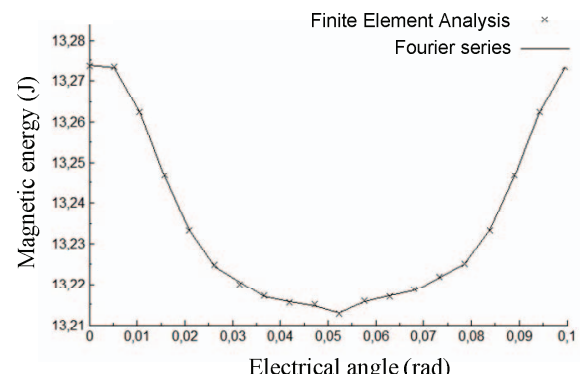

Fig. 3. Magnetic energy variation over a slot pitch of the AFPM reference machine.

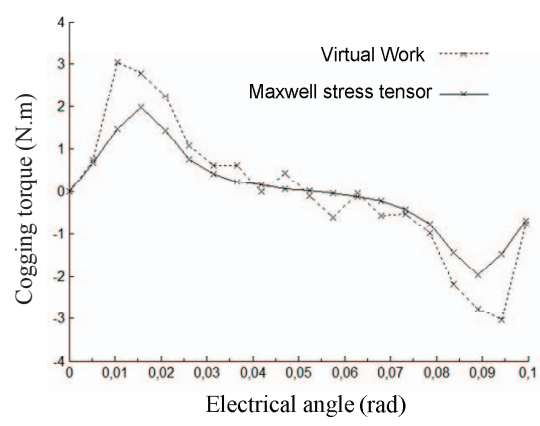

Fig. 4. Cogging torque of the AFPM machine obtained by the Maxwell stress tensor and the virtual work methods.

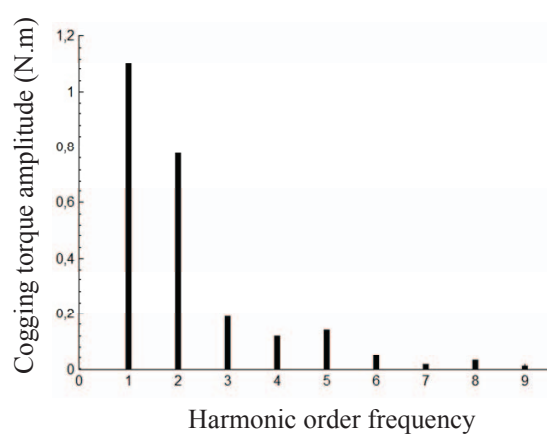

Fig. 5. Harmonic content of the cogging torque of the AFPM reference machine.

From the obtained results, it can be seen that the method of virtual work, compared with MST method, overestimates the amplitude of the cogging torque in a considerable extent 
(33.3\%), even though the wave forms are similar. As mentioned before, for this kind of application, the method of virtual work is more susceptible to inaccuracies than the MST method. Therefore, to predict the cogging torque of a PM machine through FEA results, the MST method should be preferred, as long as the magnetic flux density components in the integration domain are obtained through a high mesh density.

The design configuration under analysis does not include any mitigation technique and, therefore, a high amplitude of the cogging torque would be expected. The cogging torque amplitude obtained by the MST is 2 N.m which represents $18.2 \%$ of the average electromagnetic torque.

\section{CONCLUSION}

Main design variables able to influence the cogging torque in AFPM machines have been presented and cogging torque suppression techniques have been reviewed and discussed.

In order to evaluate the cogging torque in an AFPM machine, a comprehensive analysis of the computation techniques based on FEA accurate field solutions have been performed, outlining the advantages of MST integration over virtual work method. These methodologies have been applied to a double-sided, internal rotor, AFPM reference machine with one slot per pole and phase. The modeled configuration establishes the referential prior to introducing cogging torque mitigation techniques. From the obtained results, it is possible to conclude that the method of the virtual work overestimates the cogging torque in a large extent and MST method is, intrinsically, more accurate.

Further investigation will test and simulate various cogging torque mitigation techniques.

\section{REFERENCES}

[1] G. Mandic, et al., "Active Torque Control for Gearbox Load Reduction in a Variable-Speed Wind Turbine," IEEE Transactions on Industry Applications, vol. 48, pp. 2424-2432, 2012.

[2] T. Arakawa, et al., "Examination of an Interior Permanent Magnet Type Axial Gap Motor for the Hybrid Electric Vehicle," IEEE Transactions on Magnetics, vol. 47, pp. 3602-3605, 2011.

[3] S. Ruoho, et al., "Interdependence of Demagnetization, Loading, and Temperature Rise in a Permanent-Magnet Synchronous Motor," IEEE Transactions on Magnetics, vol. 46, pp. 949-953, 2010.

[4] S. Chaithongsuk, et al., "Optimal Design of Permanent Magnet Motors to Improve Field-Weakening Performances in Variable Speed Drives," IEEE Transactions on Industrial Electronics, vol. 59, pp. 2484-2494, 2012.

[5] A. Parviainen and P. Kontkanen, "Axial Flux Permanent Magnet Generator for Wind Power Applications," Flux Magazine, pp. 4-5, January, 20052005.
[6] Z. Q. Zhu and D. Howe, "Halbach permanent magnet machines and applications: a review," Electric Power Applications, IEE Proceedings, vol. 148, pp. 299-308, 2001.

[7] S. Sadeghi and L. Parsa, "Multiobjective Design Optimization of Five-Phase Halbach Array Permanent-Magnet Machine," IEEE Transactions on Magnetics vol. 47, pp. 1658-1666, 2011.

[8] Z. Q. Zhu, et al., "Performance of Halbach Magnetized Brushless AC Motors," IEEE Transactions on Magnetics, vol. 39, pp. 2992-2994, September, 20032003.

[9] Y. Chen and P. Pillay, "Axial-Flux PM Wind Generator with a Soft Magnetic Composite Core," in IEEE Industry Applications Conference, 40th IAS Annual Meeting, 2005, pp. 231-237.

[10] H. Xie, et al., "Research of Asymmetrical Bidirectional Magnet Skewing Technique in Modular Multi-Stage Axial Flux Permanent Magnet Synchronous Motor," IEEE Transactions on Magnetics, vol. 51, pp. 1-5, 2015 .

[11] A. M. El-Refaie, "Fractional-Slot Concentrated-Windings Synchronous Permanent Magnet Machines: Opportunities and Challenges," IEEE Transactions on Industrial Electronics, vol. 57, pp. 107-121, 2010.

[12] L. Alberti, et al., "Design of a Low-Torque-Ripple Fractional-Slot Interior Permanent-Magnet Motor," IEEE Transactions on Industry Applications, vol. 50, pp. 1801-1808, 2014.

[13] A. P. Ferreira and A. F. Costa, "Efficient Pole-Arc Coefficients for Maximum No Load Flux Linkage in Axial Flux Permanent Magnet Machines," in 8th IEEE International Symposium on Diagnostics for Electrical Machines, Power Electronics and Drives - SDEMPED 2011, Bologna, Italy, 2011.

[14] A. P. Ferreira and A. F. Costa, "Electromagnetic Finite Element Design of Axial Flux Permanent Magnet Machines for Low Speed Applications," in 2014 International Conference on Electrical Machines (ICEM), Berlin, 2014, pp. 1139-1145.

[15] R. Krishnan, Permanent Magnet Synchronous and Brushless DC Motor Drives: CRC Press, 2010.

[16] M. Aydin, et al., "Minimization of Cogging Torque in Axial-Flux Permanent-Magnet Machines: Design Concepts," IEEE Transactions on Magnetics, vol. 43, pp. 3614-3622, September, 20072007.

[17] M. Aydin and M. Gulec, "Reduction of Cogging Torque in DoubleRotor Axial-Flux Permanent-Magnet Disk Motors: A Review of Cost-Effective Magnet-Skewing Techniques With Experimental Verification," IEEE Transactions on Industrial Electronics, vol. 61, pp. 5025-5034, 2014.

[18] W. Fei and P. Luk, "A New Technique of Cogging Torque Suppression in Direct-Drive Permanent-Magnet Brushless Machines," IEEE Transactions on Industry Applications, vol. 46, pp. 1332-1340, 2010.

[19] A. Mahmoudi, et al., "Design, Analysis, and Prototyping of an AxialFlux Permanent Magnet Motor Based on Genetic Algorithm and Finite-Element Analysis," IEEE Transactions on Magnetics, vol. 49, pp. 1479-1492, 2013.

[20] J. R. J. Hendershot and T. J. E. Miller, Design of Brushless Permanent-Magnet Motors: Magna Physics Publications and Oxford Science Publications, 1994.

[21] D. A. Gonzalez, et al., "Design Consideration to Reduce Cogging Torque in Axial Flux Permanent-Magnet Machines," IEEE Transactions on Magnetics, vol. 43, pp. 3435-3440, August, 2007 2007.

[22] E. P. Furlani, Permanent Magnet and Electromechanical Devices: Academic Press, 2001.

[23] D. A. Lowther and P. P. Silvester, Computer-Aided Design in Magnetics. New York: Springer-Verlag, 1986.

[24] COMSOL. (December, 2013). COMSOL Multiphysics. Available: http://www.comsol.com/products 